\title{
Organic Nanowire-Templated Fabrication of Alumina Nanotubes by Atomic Layer Deposition
}

Chih-Chieh Wang ${ }^{a}$, Chi-Chung Ke ${ }^{a, b}$, Ya-Wen Yu ${ }^{a}$, and Tsong-Pyng Perng ${ }^{a, c, *}$

${ }^{\mathrm{a}}$ Department of Materials Science and Engineering, National Tsing Hua University

Hsinchu 300, Taiwan

${ }^{\mathrm{b}}$ Instrument Technology Research Center, National Applied Research Laboratories

Hsinchu 300, Taiwan

${ }^{c}$ Department of Chemical Enginnering and Materials Science, Yuan Ze University

Chung-Li 320, Taiwan

Content

Figure $\mathrm{S} 1$. SEM images of $\mathrm{GaQ}_{3}$ nanowires prepared under different helium pressures.

(a) $9.3 \mathrm{kPa}, \mathrm{d}_{\mathrm{avg}}=30-40 \mathrm{~nm}$, (b) $10.3 \mathrm{kPa}, \mathrm{d}_{\mathrm{avg}}=40-50 \mathrm{~nm}$ and (c) $11.3 \mathrm{kPa}, \mathrm{d}_{\text {avg }}=60-70 \mathrm{~nm}$. 

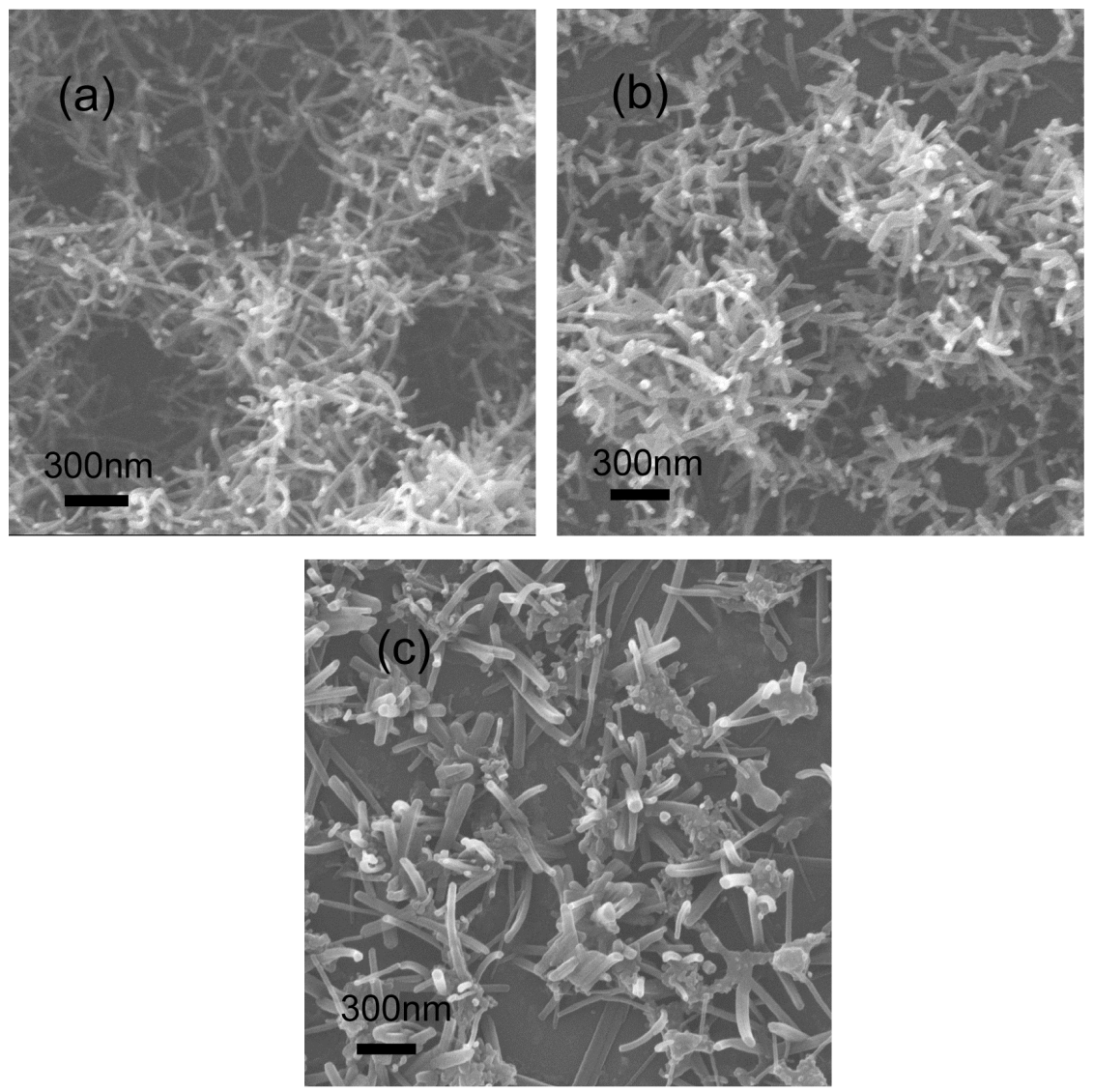

Figure $\mathrm{S} 1$. SEM images of $\mathrm{GaQ}_{3}$ nanowires prepared under different helium pressures.

(a) $9.3 \mathrm{kPa}, \mathrm{d}_{\mathrm{avg}}=30-40 \mathrm{~nm}$, (b) $10.3 \mathrm{kPa}, \mathrm{d}_{\mathrm{avg}}=40-50 \mathrm{~nm}$ and (c) $11.3 \mathrm{kPa}, \mathrm{d}_{\mathrm{avg}}=60-70 \mathrm{~nm}$. 